\title{
Raman spectra of the GFP-like fluorescent proteins
}

\author{
Ye Yuan ${ }^{1,2}$, Dianbing Wang ${ }^{1}$, Jibin Zhang ${ }^{2}$, Ji Liu ${ }^{1,3}$, Jian Chen ${ }^{3}$, Xian-En Zhang ${ }^{1 \bowtie}$ \\ ${ }^{1}$ National Laboratory of Biomacromolecules, CAS Center for Excellence in Biomacromolecules, Institute of \\ Biophysics, Chinese Academy of Sciences, Beijing 100101, China \\ 2 College of Life Science and Technology, Huazhong Agricultural University, Wuhan 430070, China \\ ${ }^{3}$ College of Life Science, Hubei University, Wuhan 430070, China
}

Received: 17 July 2018 / Accepted: 20 August 2018 / Published online: 2 November 2018

\begin{abstract}
The objective of the study was to elucidate optical characteristics of the chromophore structures of fluorescent proteins. Raman spectra of commonly used GFP-like fluorescent proteins (FPs) with diverse emission wavelengths (green, yellow, cyan and red), including the enhanced homogenous FPs EGFP, EYFP, and ECFP (from jellyfish) as well as mNeptune (from sea anemone) were measured. High-quality Raman spectra were obtained and many marker bands for the chromophore of the FPs were identified via assignment of Raman spectra bands. We report the presence of a positive linear correlation between the Raman band shift of $\mathrm{C}_{5}=\mathrm{C}_{6}$ and the excitation energy of FPs, demonstrated by plotting absorption maxima $\left(\mathrm{cm}^{-1}\right)$ against the position of the Raman band $\mathrm{C}_{5}=\mathrm{C}_{6}$ in EGFP, ECFP, EYFP, the anionic chromophore and the neutral chromophore. This study revealed new Raman features in the chromophores of the observed FPs, and may contribute to a deeper understanding of the optical properties of FPs.
\end{abstract}

Keywords Raman spectra, Fluorescent protein, Chromophore

\section{INTRODUCTION}

The Raman spectrum provides a "fingerprint" of the vibration and rotation of molecules. The conformation and structure of biomacromolecules such as DNA, protein chains, membrane proteins and lipids, as well as other structural data related to such molecules can be obtained using Raman spectroscopy (Bunaciu et al. 2015; Carey 1982; Tu 1982; Tuma 2005; Xu 2005).

In recent years, the Raman spectra of fluorescent proteins (FPs) have attracted much attention due to the unique optical properties of FPs and their wider applicability in molecular and cellular imaging. Analysis of the Raman spectra of GFP and its mutants revealed that

National Laboratory of Biomacromolecules, CAS Center for Excellence in Biomacromolecules, Institute of Biophysics, Chinese Academy of Sciences and College of Life Science and Technology, Huazhong Agricultural University contributed equally to this paper.

$\bowtie$ Correspondence: zhangxe@ibp.ac.cn (X.-E. Zhang) the ground-state structure of the anionic form of the chromophore may be heavily dependent on the chromophore environment Bell et al. 2000). Femtosecondstimulated Raman spectroscopy showed that skeletal motions are related to proton transfers which makes GFP in the fluorescent form (Fang et al. 2009). In addition, the Raman spectra of the red fluorescent protein, eqFP611, from the sea anemone, Entacmaea quadricolor, revealed photoinduced cis-trans isomerization of the chromophore (Davey et al. 2006). Resonance and pre-resonance Raman spectra of the photochromic fluorescent protein, Dronpa, demonstrated enhanced Raman band selectively for the chromophore, thus yielding important information on the chromophore structure (Higashino et al. 2016).

Based on the above findings, our focus was directed at the relationship between emission wavelengths of FPs and their Raman spectrum characteristics. To clarify this relationship, we measured the Raman spectra of a group of commonly used GFP-like FPs with diverse emission wavelengths (green, yellow, cyan, and red), 
including the enhanced homogenous fluorescent proteins EGFP, EYFP, and ECFP (from jellyfish) to mNeptune (from anemone). It is felt that the results of this study may not only enrich the understanding of Raman spectra in relation to FPs, but also benefit efforts associated with the rational design and directed evolution of FPs for practical purposes.

\section{RESULTS AND DISCUSSION}

\section{Raman spectra of fluorescent proteins}

Raman spectra of EGFP, ECFP, and EYFP are shown (Fig. 1). Assignment of Raman bands for these FPs are presented (Table 1). Raman spectroscopy with 785-nm excitation was used to acquire the Raman spectra of FPs. This excitation wavelength selectively enhances the intensity of vibrational bands originating in the chromophore, and thereby avoids certain issues associated with strictly on-resonance Raman experiments such as fluorescence, photoisomerization, or sample degradation (Bell et al. 2000). As a result, most Raman spectra bands obtained in the study were produced by the chromophores of FPs, and only a few Raman spectra bands were due to the main chain groups and side chain groups on the $\beta$-barrel of fluorescent proteins. The Raman spectra bands of EGFP at $1664 \mathrm{~cm}^{-1}$, ECFP at $1662 \mathrm{~cm}^{-1}$ and EYFP at $1659 \mathrm{~cm}^{-1}$ are all assigned to Amide I modes (Table 1). The Raman spectra bands of EGFP at $1447 \mathrm{~cm}^{-1}$, ECFP at $1450 \mathrm{~cm}^{-1}$ and EYFP at $1446 \mathrm{~cm}^{-1}$ are assigned to side-chain $\mathrm{CH}_{2}$ group modes. The Raman spectra band at $1004 \mathrm{~cm}^{-1}$ is assigned to the aromatic side-chain mode of the FPs. The Raman spectra bands among $1220-1350 \mathrm{~cm}^{-1}$ were from Amide III.

The chromophores of EGFP, EYFP, and mNeptune are mainly composed of the phenol group and the imidazolinone ring formed by propylene group bridging. As the phenol group consists of $\mathrm{C}, \mathrm{H}$, and $\mathrm{O}$, the Raman spectra bands from the phenol group are due to the vibration of the phenol ring, $\mathrm{C}-\mathrm{H}$ bonds of the phenol group, and the phenolic hydroxyl group. For example, the Raman spectra bands of EGFP at 618,1035, 1128
Fig. 1 Raman spectra of EGFP, ECFP and EYFP

$$
\text { - EYFP }
$$

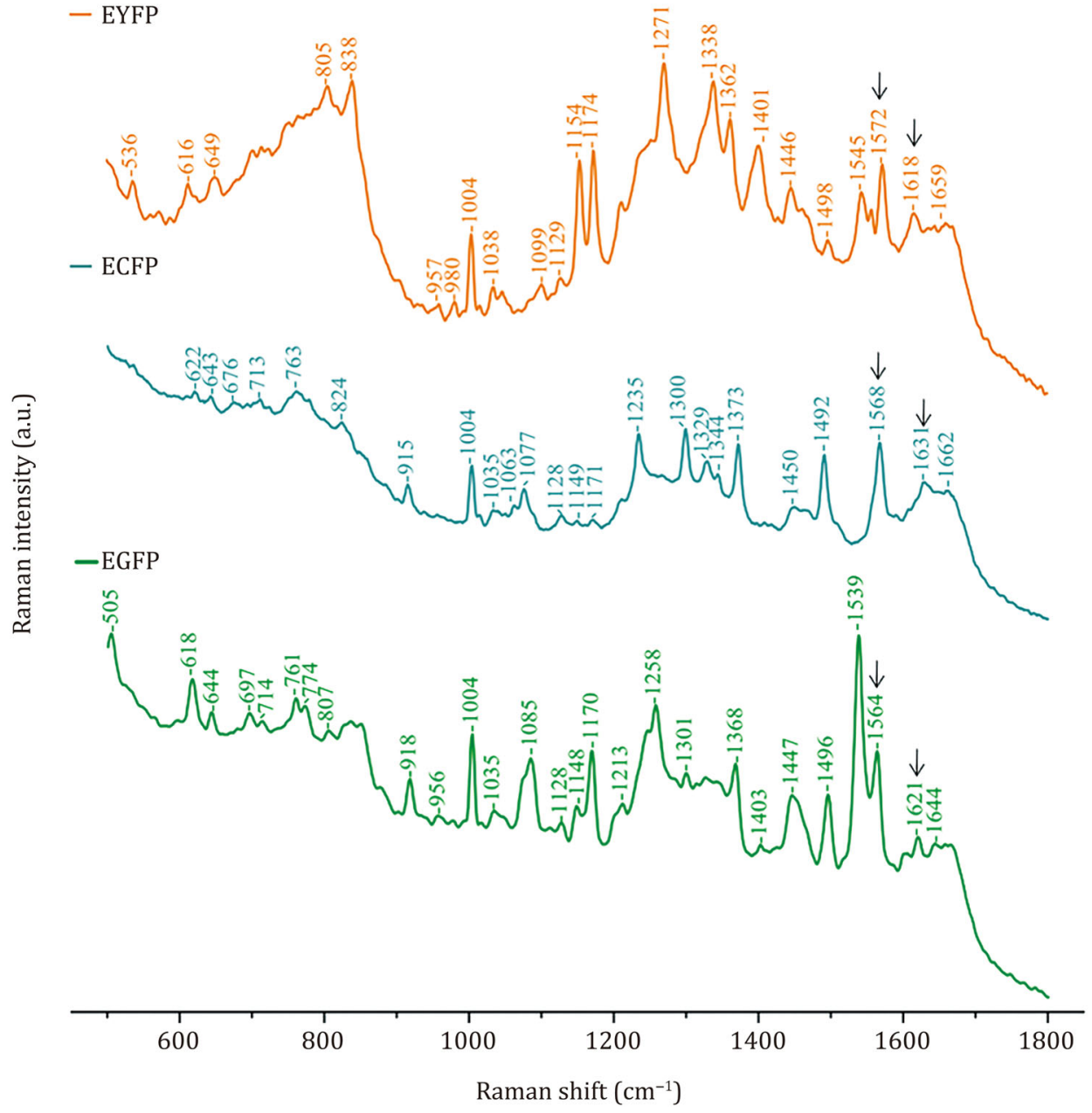


Table 1 Raman shifts and mode assignments of EGFP, ECFP and EYFP
${ }^{a} \mathrm{Ph}$ : Phenol

${ }^{b}$ str: stretch

${ }^{c}$ def: deformation

\begin{tabular}{|c|c|c|c|}
\hline EGFP & ECFP & EYFP & Mode assignment \\
\hline 618 & 622 & 616 & $\mathrm{Ph}^{a} \mathrm{C}-\mathrm{H}$ in-plane $\mathrm{H}$ bend \\
\hline \multirow[t]{2}{*}{644} & 643 & & $\mathrm{Ph} \mathrm{C}-\mathrm{H}$ in-plane $\mathrm{H}$ bend \\
\hline & & 649 & $-\mathrm{C}=\mathrm{C} \mathrm{str}^{b}$ \\
\hline 697 & & & $-\mathrm{N}-\mathrm{H} \operatorname{def}^{c}$ \\
\hline \multirow[t]{3}{*}{807} & & 805 & $-\mathrm{C}-\mathrm{H}$ out-of-plane def \\
\hline & & 838 & $-\mathrm{C}-\mathrm{H}$ out-of-plane def \\
\hline & & 980 & $-\mathrm{C}-\mathrm{H}$ in-plane $\mathrm{H}$ bend \\
\hline 1004 & 1004 & 1004 & Aromatic side-chain mode of protein \\
\hline \multirow[t]{3}{*}{1035} & 1035 & 1038 & $-\mathrm{C}-\mathrm{H}$ in-plane $\mathrm{H}$ bend \\
\hline & 1077 & & $-\mathrm{C}-\mathrm{H}$ in-plane $\mathrm{H}$ bend \\
\hline & & 1099 & $-\mathrm{C}-\mathrm{H}$ in-plane $\mathrm{H}$ bend \\
\hline \multirow[t]{2}{*}{1128} & 1128 & 1129 & $-\mathrm{C}-\mathrm{H}$ in-plane $\mathrm{H}$ bend, $\mathrm{Ph}$ ring- $\mathrm{H}$ scissor \\
\hline & & 1154 & $\mathrm{Ph} \mathrm{C}-\mathrm{H}$ in-plane $\mathrm{H}$ bend, Bridge $\mathrm{C} 6-\mathrm{H}$ rock, imidazolinone ring, $\mathrm{C} 12 \mathrm{OH}$ rock \\
\hline 1148 & 1149 & & $-\mathrm{C}-\mathrm{H}$ in-plane $\mathrm{H}$ bend \\
\hline 1170 & 1171 & 1174 & $\mathrm{Ph}$ ring- $\mathrm{H}$ bend, Bridge $\mathrm{C} 6-\mathrm{H}$ rock, $\mathrm{Ph} \mathrm{C}-\mathrm{H}$ def, imidazolinone ring def \\
\hline \multirow[t]{2}{*}{1213} & & & $-\mathrm{C}-\mathrm{H}$ in-plane $\mathrm{H}$ bend \\
\hline & 1235 & & Ring combination bend-str \\
\hline \multirow[t]{2}{*}{1258} & & & $-\mathrm{C}-\mathrm{H}$ in-plane $\mathrm{H}$ bend \\
\hline & & 1271 & $-\mathrm{C}-\mathrm{H}$ bend \\
\hline \multirow[t]{3}{*}{1301} & 1300 & & $\mathrm{Ph}$ ring-H bend \\
\hline & 1329 & & $-\mathrm{C}-\mathrm{N}-\mathrm{H}$ str \\
\hline & & 1338 & -C6-H rock \\
\hline 1368 & & 1362 & $\mathrm{C}-\mathrm{O}-\mathrm{H}$ def $(\mathrm{O}-\mathrm{H}$ bend and $\mathrm{C}-\mathrm{O}$ str, $\mathrm{Ph}$ hydroxyl group) \\
\hline 1403 & & 1401 & Ring combination bend-str \\
\hline 1447 & 1450 & 1446 & Side chain $\mathrm{CH} 2$ group \\
\hline 1496 & 1492 & 1498 & $\mathrm{Ph}$ ring str \\
\hline \multirow[t]{2}{*}{1539} & & & Imidazolinone $+\mathrm{C}=\mathrm{C}$ str \\
\hline & & 1545 & $-\mathrm{C}-\mathrm{N}-\mathrm{H}$ str \\
\hline 1564 & 1568 & 1572 & $-\mathrm{C} 3=\mathrm{N} 1 \mathrm{str}$ \\
\hline 1621 & 1631 & 1618 & $\mathrm{C} 5=\mathrm{C} 6 \mathrm{str}$ \\
\hline 1644 & 1662 & 1659 & $-\mathrm{C} 4=013 \mathrm{str}$ \\
\hline
\end{tabular}

and $1170 \mathrm{~cm}^{-1}$, EYFP at 616,1038, 1129 and $1174 \mathrm{~cm}^{-1}$ and mNeptune at 621, 1107, 1119, 1156, and $1170 \mathrm{~cm}^{-1}$ are likely assigned to a $\mathrm{C}-\mathrm{H}$ phenol bending mode. The bands of EGFP at $1496 \mathrm{~cm}^{-1}$, EYFP at $1498 \mathrm{~cm}^{-1}$ and mNeptune at $1480 \mathrm{~cm}^{-1}$ are assigned to a phenol ring stretching mode.

To configure the marker bands of the chromophore, the Raman spectra bands of ECFP were compared with those of EGFP, and EYFP. It was found that the band at $1368 \mathrm{~cm}^{-1}$ of EGFP and the band at $1362 \mathrm{~cm}^{-1}$ of EYFP were from stretching vibrations of the phenolic hydroxyl group on the side chain of 66Tyr in the chromophore. However, the bands of ECFP around $1368 \mathrm{~cm}^{-1}$ or $1362 \mathrm{~cm}^{-1}$ did not appear, due to the presence of an indolyl group, rather than a phenol group, on the side chain of 66Trp. Therefore, the band of
ECFP at $1329 \mathrm{~cm}^{-1}$ due to the stretching vibration of indolyl $\mathrm{C}-\mathrm{N}-\mathrm{H}$ on the side chain of 66Trp, is likely a marker band of ECFP. In addition, there were other differences between the Raman spectra of EGFP, ECFP, and EYFP. For example, $\mathrm{C}_{3}=\mathrm{N}_{1}$ stretching of EGFP, ECFP, and EYFP each produced a Raman band at 1564, 1568 and $1572 \mathrm{~cm}^{-1}$, respectively; $\mathrm{C}_{5}=\mathrm{C}_{6}$ stretching of EGFP, ECFP, and EYFP each produced a Raman band at 1621, 1631 and $1618 \mathrm{~cm}^{-1}$, respectively; also, $\mathrm{C}_{4}=\mathrm{O}_{13}$ stretching of EGFP, ECFP, and EYFP each produced a Raman band at 1644,1662 and $1659 \mathrm{~cm}^{-1}$, respectively. These results suggested that EGFP, EYFP, and ECFP may each have their respective featured Raman bands, and therefore may be distinguished by a comparison of their Raman spectra, although these enhanced FPs are highly homogenous. These features in 
the Raman spectra of FPs were strongly dependent on the environment, as well as the structure of the chromophore.

We also measured the Raman spectra of mNeptune, which is a GFP-like protein, originating in a sea anemone. As expected, its Raman spectrum was significantly different from that of EGFP, as the two FPs originated in different species (Fig. 2 and Table 2). Assignment of the Raman bands indicated that the bands of mNeptune at 1170, 1156 and $1201 \mathrm{~cm}^{-1}$ are marker bands, by which mNeptune may be distinguished from EGFP. Besides, mNeptune produced many Raman bands at $1320-1370 \mathrm{~cm}^{-1}$ which arose from the imidazolinone ring-related groups, whereas EGFP produced more bands at $1400-1500 \mathrm{~cm}^{-1}$ due to the presence of 66Tyr in its chromophore. We, therefore, hypothesized that different features in the Raman spectra of EGFP and mNeptune were mainly due to differences in their chromophore structures which resulted in obviously different molecular vibrations.

\section{Linear correlation between the Raman band shift of $\mathrm{C}_{5}=\mathrm{C}_{6}$ in the chromophores and the excitation energy for FPs}

The Raman band of $\mathrm{C}_{5}=\mathrm{C}_{6}$ in the chromophore is at $1621 \mathrm{~cm}^{-1}$ for EGFP, $1631 \mathrm{~cm}^{-1}$ for ECFP and $1618 \mathrm{~cm}^{-1}$ for EYFP (Tables 1, 3). A previous study illustrated that the Raman band of $\mathrm{C}_{5}=\mathrm{C}_{6}$ in the anionic chromophore form is at $1628 \mathrm{~cm}^{-1}$ and the band in the neutral chromophore form is at $1648 \mathrm{~cm}^{-1}$ (Bell et al. 2000). There was a positive linear correlation between the absorption maxima $\left(\mathrm{cm}^{-1}\right)$ and the position of the Raman band of $\mathrm{C}_{5}=\mathrm{C}_{6}$ in EGFP, ECFP, EYFP, the anionic chromophore form, and the neutral chromophore form (Fig. 3).

Excitation energy is dependent on the chromophore structure of the FP and its surrounding microenvironment, which is related to the absorption maximum. In the chromophore of EGFP, Tyr presents a conjugated ring with $\pi$ electrons because of the connection of the imidazolidone ring and the phenolic group of 66Tyr by $\mathrm{C}_{5}=\mathrm{C}_{6}$. In this conjugated ring, the dihedral angle of $\mathrm{C}_{4}-$ $\mathrm{C}_{5}=\mathrm{C}_{6}-\mathrm{C}_{7}$ is $177.67^{\circ}$ (Arpino et al. 2012). As a comparison, the dihedral angle in ECFP is $173.38^{\circ}$ (Lelimousin et al. 2009). Therefore, the $\pi$-conjugated plane in the chromophore of EGFP is larger than that of ECFP, illustrating lower excitation energy needed for EGFP. However, EYFP requires even lower excitation energy than EGFP, as $\pi$-stacking interaction between the chromophore and 203Tyr of EYFP leads to a more stable electronic state (Wachter et al. 1998). For these reasons, we postulate that the presence of a linear correlation demonstrates a direct relationship between the Raman band shift of $\mathrm{C}_{5}=\mathrm{C}_{6}$ and the excitation energy for FPs (Fig. 3). Obviously, the lower the excitation
Fig. 2 Raman spectra of mNeptune and EGFP

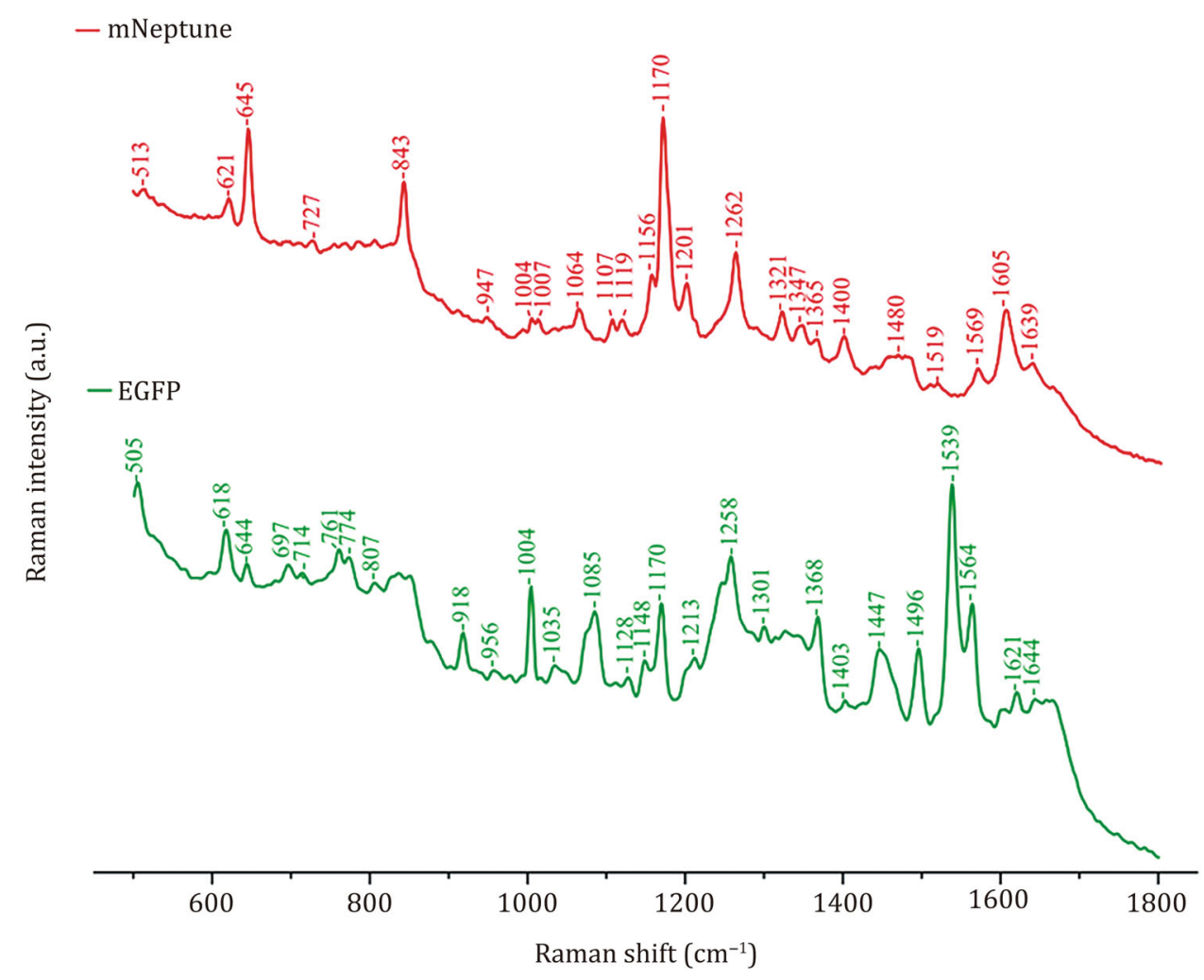


Table 2 Raman shifts and mode assignments of EGFP and mNeptune
${ }^{a} \mathrm{Ph}$ : Phenol

${ }^{b}$ def: deformation

${ }^{c}$ str: stretch

\begin{tabular}{|c|c|c|}
\hline EGFP & mNeptune & Mode assignment \\
\hline 618 & 621 & $\mathrm{Ph}^{a} \mathrm{C}-\mathrm{H}$ in-plane $\mathrm{H}$ bend \\
\hline 644 & & $\mathrm{Ph} \mathrm{C}-\mathrm{H}$ in-plane $\mathrm{H}$ bend \\
\hline 697 & & $-\mathrm{N}-\mathrm{H} \mathrm{def}^{b}$ \\
\hline \multirow[t]{3}{*}{807} & & $-\mathrm{C}-\mathrm{H}$ out-of-plane def \\
\hline & 645 & $\mathrm{CH}=\mathrm{CH}$ def cis in-phase wag \\
\hline & 843 & $-\mathrm{C}-\mathrm{O}$ skeletal $\mathrm{str}^{c}$ \\
\hline 1004 & 1004 & Aromatic side chain mode \\
\hline \multirow[t]{3}{*}{1035} & & $-\mathrm{C}-\mathrm{H}$ in-plane $\mathrm{H}$ bend \\
\hline & 1107 & $-\mathrm{C}-\mathrm{H}$ in-plane $\mathrm{H}$ bend \\
\hline & 1119 & $-\mathrm{C}-\mathrm{H}$ in-plane $\mathrm{H}$ bend \\
\hline 1128 & & $-\mathrm{C}-\mathrm{H}$ in-plane $\mathrm{H}$ bend, $\mathrm{Ph}$ ring- $\mathrm{H}$ scissor \\
\hline \multirow[t]{2}{*}{1148} & & $-\mathrm{C}-\mathrm{H}$ in-plane $\mathrm{H}$ bend \\
\hline & 1156 & $\mathrm{Ph} \mathrm{C}-\mathrm{H}$ in plane $\mathrm{H}$ bend, Bridge $\mathrm{C}_{6}-\mathrm{H}$ rock, imidazolinone ring def, $\mathrm{C}_{12} \mathrm{OH}$ rock \\
\hline \multirow[t]{2}{*}{1170} & 1170 & $\mathrm{Ph}$ ring- $\mathrm{H}$ bend(rock), Bridge $\mathrm{C}_{6}-\mathrm{H}$ rock, $\mathrm{Ph} \mathrm{C}-\mathrm{H}$ def; \\
\hline & 1201 & $-\mathrm{C}-\mathrm{N}$ str \\
\hline 1213 & & $-\mathrm{C}-\mathrm{H}$ in-plane $\mathrm{H}$ bend \\
\hline \multirow[t]{2}{*}{1258} & & $-\mathrm{C}-\mathrm{H}$ in-plane $\mathrm{H}$ bend \\
\hline & 1262 & Phenol $\mathrm{C}-\mathrm{H}, \mathrm{Ph}$ ring $\mathrm{C}_{12}-\mathrm{O}$ stretch, $\mathrm{Ph}$ ring- $\mathrm{H}$ rock \\
\hline \multirow[t]{4}{*}{1301} & & $\mathrm{Ph}$ ring- $\mathrm{H}$ bend \\
\hline & 1321 & $-\mathrm{C}-\mathrm{N}$ str \\
\hline & 1347 & $-\mathrm{C}-\mathrm{H}$ rock \\
\hline & 1365 & $-\mathrm{C}-\mathrm{O}-\mathrm{H} \mathrm{def}^{\mathrm{a}}$ \\
\hline \multirow[t]{2}{*}{1368} & & $\mathrm{C}-\mathrm{O}-\mathrm{H}$ def $(\mathrm{O}-\mathrm{H}$ bend and $\mathrm{C}-\mathrm{O}$ str, $\mathrm{Ph}$ hydroxyl group $)$ \\
\hline & 1400 & Ring combination bend-str; $\mathrm{C}_{12} \mathrm{OH}$ rock \\
\hline 1403 & & Ring combination bend-str \\
\hline \multirow[t]{2}{*}{1447} & & Side chain $\mathrm{CH}_{2}$ group \\
\hline & 1480 & $\mathrm{Ph}$ ring \\
\hline 1496 & & $\mathrm{Ph}$ ring str \\
\hline 1539 & & Imidazolinone $+\mathrm{C}=\mathrm{C}$ str \\
\hline \multirow[t]{3}{*}{1564} & & $-\mathrm{C}_{3}=\mathrm{N}_{1} \mathrm{str}$ \\
\hline & 1569 & Ring combination bend-str \\
\hline & 1605 & $\mathrm{C}=\mathrm{C}$ \\
\hline \multirow[t]{2}{*}{1621} & & $\mathrm{C}_{5}=\mathrm{C}_{6} \mathrm{str}$ \\
\hline & 1639 & Amide I \\
\hline 1644 & & $-\mathrm{C} 4=\mathrm{O}_{13} \mathrm{str}$ \\
\hline
\end{tabular}

energy, the bigger the redshift of $\mathrm{C}_{5}=\mathrm{C}_{6}$ stretching mode, and vice versa.

\section{Analysis of the correlation between the Raman band shift of $\mathrm{C}_{3}=\mathrm{N}_{1}$ in chromophore and the photostability of FPs}

The protonation of $\mathrm{N}_{1}$ in the chromophore of enhanced FPs plays an important role in chromophore stability, and exerts an effect on some optical properties of FPs (Wachter et al. 1998). We consider the interactions of $\mathrm{N}_{1}$ with its surrounding amino-acid residues and $\mathrm{H}_{2} \mathrm{O}$ may further stabilize the structure of the chromophore. Some evidence for this can be found in the Raman spectra of the FPs. For instance, the band at $1564 \mathrm{~cm}^{-1}$ in EGFP is a $\mathrm{C}_{3}=\mathrm{N}_{1}$ stretching mode (Table 3). However, the $\mathrm{C}_{3}=\mathrm{N}_{1}$ stretching mode is shifted to $1568 \mathrm{~cm}^{-1}$ in ECFP and to $1572 \mathrm{~cm}^{-1}$ in EYFP, respectively. It is evident from the chromophore hydrogen bond network of FPs that $\mathrm{N}_{1}$ and $\mathrm{H}_{2} \mathrm{O}$ form a hydrogen bond, through which $\mathrm{H}_{2} \mathrm{O}$ absorbs electrons from $\mathrm{N}_{1}$ (Fig. 4). This electron attraction effect causes a redshift of the $\mathrm{C}_{3}=\mathrm{N}_{1}$ mode, whereas such an effect is not observed in EYFP's Raman spectrum, because EYFP lacks such a hydrogen 
Table 3 Comparison of characteristics of EGFP, ECFP and EYFP

\begin{tabular}{|c|c|c|c|c|c|}
\hline \multirow[t]{2}{*}{ FPs } & \multirow[t]{2}{*}{ Scheme of chromophore } & \multirow[t]{2}{*}{$\lambda_{\mathrm{ex}} / \lambda_{\mathrm{em}}{ }^{a}(\mathrm{~nm})$} & \multicolumn{2}{|c|}{ Raman bands } & \multirow[t]{2}{*}{ Raman spectra } \\
\hline & & & $\mathrm{C}_{3}=\mathrm{N}_{1}$ & $\mathrm{C}_{5}=\mathrm{C}_{6}$ & \\
\hline EGFP & & $489 / 508$ & $1564 \mathrm{~cm}^{-1}$ & $1621 \mathrm{~cm}^{-1}$ & \\
\hline ECFP & & $434 / 477$ & $1568 \mathrm{~cm}^{-1}$ & $1631 \mathrm{~cm}^{-1}$ & \\
\hline EYFP & & $514 / 537$ & $1572 \mathrm{~cm}^{-1}$ & $1618 \mathrm{~cm}^{-1}$ & 1 \\
\hline
\end{tabular}

${ }^{a}$ Excitation and emission maxima (Voityuk et al. 1998)

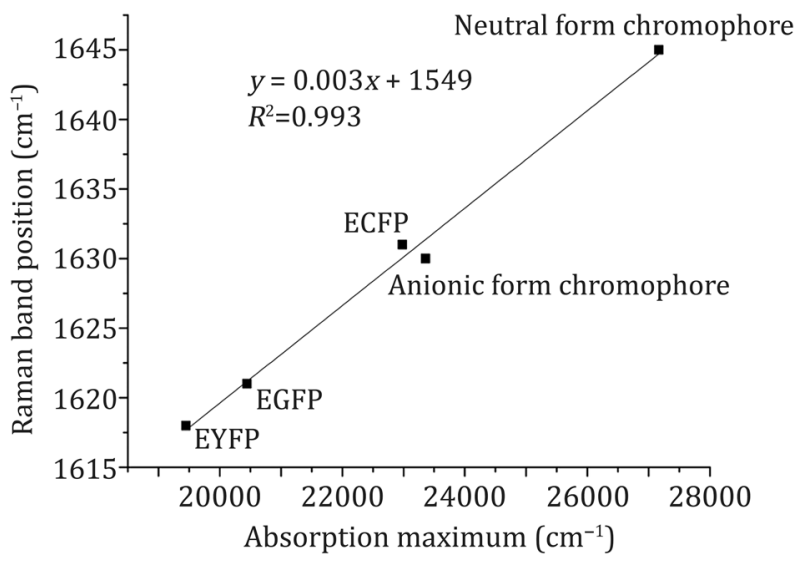

Fig. 3 Plot of absorption maxima versus $C_{5}=C_{6}$ Raman band position for neutral form of chromophore, anionic form of chromophore, EGFP, ECFP and EYFP

bond. The length of the hydrogen bond in EGFP is $3.43 \AA$ while it is $3.52 \AA$ in ECFP, indicating a stronger attraction effect in EGFP compared to ECFP. Therefore, the $\mathrm{C}_{3}=\mathrm{N}_{1}$ mode in EGFP presents a bigger redshift compared to that of ECFP. Considering the fact that the photobleaching time ratio of ECFP to EGFP is 0.85, whereas the ratio of EYFP to EGFP is only 0.35 (Patterson et al. 2001), we propose that the redshift of the $\mathrm{C}_{3}=\mathrm{N}_{1}$ mode in the chromophore may possibly be related to the photostability of FPs. However, this contention may require further validation via experimental data.

\section{CONCLUSION}

In summary, high-quality Raman spectra of a group of GFP-like FPs were obtained. Raman spectra of the FPs derived from GFP were evidently distinct from the RFP (mNeptune). Some marker bands were also found in the Raman spectra of GFP-derived FPs. These marker bands are mainly produced by their distinct chromophores. Among these bands, the Raman band shift of $C_{5}=C_{6}$ presents a positive linear correlation with the excitation energy for FPs. This study not only reveals new Raman features in the chromophore, but also illustrates the relationship between these features and the optical properties of FPs. 

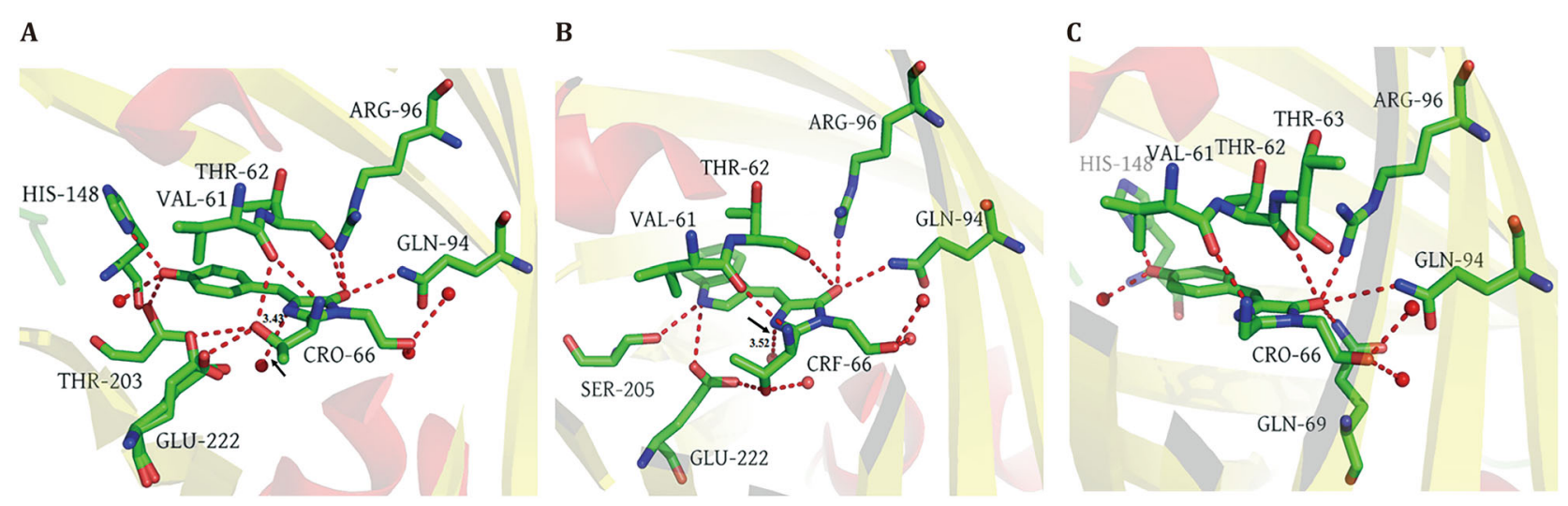

Fig. 4 Chromophore hydrogen bond network of fluorescent proteins. Red dashed lines represent hydrogen bond. Red spheres denote $\mathrm{H}_{2} \mathrm{O}$ molecule. A Chromophore hydrogen bond network of EGFP (PDB Code:4EUL). B Chromophore hydrogen bond network of ECFP (PDB Code:2WSN). C Chromophore hydrogen bond network of EYFP (PDB Code:1YFP). Black arrow indicates the hydrogen bond between N1 and $\mathrm{H}_{2} \mathrm{O}$ molecule

\section{MATERIALS AND METHODS}

\section{Reagents and materials}

The vector pQE30, containing the gene clone of FPs, was purchased from Qiagen (Hilden, Germany). E. coli TG1 was used to express FPs. The primers used in this study are listed in Table 4.

\section{Expression and purification of fluorescent proteins}

The cDNAs of FPs were cloned into the BamH I and Sac I restriction sites of the pQE30 vector, using forward primers and reverse primers, respectively (Table 4). FPs were expressed in the E. Coli TG1 strain. Bacterial cultures were grown overnight in LB media containing $100 \mu \mathrm{g} / \mathrm{mL}$ ampicillin at $180 \mathrm{r} / \mathrm{min}$ at $37^{\circ} \mathrm{C}$, and further incubated at $25{ }^{\circ} \mathrm{C}$ for $12 \mathrm{~h}$. The cells were harvested via centrifugation at $4500 \mathrm{r} / \mathrm{min}$ at $4{ }^{\circ} \mathrm{C}$ for $5 \mathrm{~min}$, and the cell pellets were resuspended in binding buffer $(20 \mathrm{mmol} / \mathrm{L}$ Tris-HCl, $500 \mathrm{mmol} / \mathrm{L} \mathrm{NaCl}$, $20 \mathrm{mmol} / \mathrm{L}$ imidazole, $\mathrm{pH}$ 8.0). Following cell lysis by French pressure (JNBIO, JN-02C, China), the FPs were purified using Ni-NTA His-Bind resin (GE Healthcare, USA) and a Superdex-200 size exclusion column (GE Healthcare, USA) according to the manufacturer's instructions. Purified proteins were characterized using SDS-polyacrylamide electrophoresis. FPs were stored in Start Buffer (20 mmol/L Tris pH 7.9; $\mathrm{NaCl} 100 \mathrm{mmol} / \mathrm{L}$ ) with concentration of $15-20 \mathrm{mg} / \mathrm{mL}$ for further analysis.

\section{Raman spectroscopy}

For Raman measurements, $45 \mu \mathrm{l}$ of protein solution was added into a sample cell and placed on the object stage. The sample was excited with a 785-nm pulsed laser at an excitation power of $50 \mathrm{~mW} / \mathrm{cm}^{2}$, as $785-\mathrm{nm}$ excitation allows probing of the chromophore site with minimal spectral interference from the surrounding protein environment.

The Raman spectra were acquired using Renishaw inVia Reflex confocal Raman microscope (Renishaw, UK) with a total collection time of $60 \mathrm{~s}$ for the recording of the spectra region from approximately $400-2400 \mathrm{~cm}^{-1}$. The laser beam was focused on the $200-300 \mu \mathrm{m}$ point under the sample surface.
Table 4 Primers used in this study

\begin{tabular}{ll}
\hline Primer name & Primer sequence $\left(5^{\prime}-3^{\prime}\right)$ \\
\hline EGFP-BamHI-F & ATATGGATCCATGGTGAGCAAGGGCGAGGA \\
EGFP-SacI-R & GAGCGAGCTCTTACTTGTACAGCTCGTCCAT \\
ECFP-BamHI-F & ATATGGATCCATGGTGAGCAAGGGCGAGGA \\
ECFP-SacI-R & GAGCGAGCTCTTACTTGTACAGCTCGTCCAT \\
EYFP-BamHI-F & ATATGGATCCATGGTGAGCAAGGGCGAG \\
EYFP-SacI-R & GCGTGAGCTCTTACTTGTACAGCTCGTCCAT \\
mNeptune-BamHI-F & ATAGGATCCATGGTGTCTAAGGGCGAAGAGCTGATTA \\
mNeptune-SacI-R & ATAGAGCTCTTACTTGTACAGCTCGTCCATGCCATTA \\
\hline
\end{tabular}


Raw data were processed by KnowItAll software, (Bio-Rad, USA) and Raman spectra were calculated by Savitzky-Golay smoothing. Raman spectra assignment was performed using KnowItAll software functional group database and references.

Acknowledgements This work was supported by the Strategic Priority Research Program of Chinese Academy of Sciences (XDPB0305, CAS). The authors are very grateful to Junfang Zhao from Technical Institute of Physics and Chemistry, CAS for technical support in Raman spectra experiments and Prof. Zhou Lu from Institute of Chemistry, CAS for his valuable suggestions.

\section{Compliance with ethical standards}

Conflict of interest Ye Yuan, Dianbing Wang, Jibin Zhang, Ji Liu, Jian Chen, Xian-En Zhang declare that they have no conflict of interest.

Human and animal rights and informed consent This article does not contain any studies with human or animal subjects performed by any of the authors.

Open Access This article is distributed under the terms of the Creative Commons Attribution 4.0 International License (http:// creativecommons.org/licenses/by/4.0/), which permits unrestricted use, distribution, and reproduction in any medium, provided you give appropriate credit to the original author(s) and the source, provide a link to the Creative Commons license, and indicate if changes were made.

\section{References}

Arpino JA, Rizkallah PJ, Jones DD (2012) Crystal structure of enhanced green fluorescent protein to $1.35 \AA$ resolution reveals alternative conformations for Glu222. PLoS ONE 7(10):e47132
Bell AF, He X, Wachter RM, Tonge PJ (2000) Probing the ground state structure of the green fluorescent protein chromophore using Raman spectroscopy. Biochemistry 39:4423-4431

Bunaciu AA, Aboulenein HY, Hoang VD (2015) Raman spectroscopy for protein analysis. Appl Spectrosc Rev 50:377-386

Carey P (1982) Biochemical applications of raman and resonance raman spectroscopes. In: Chapter 4 protein conformation from raman and resonance raman sptecta, pp 71-98

Fang C, Frontiera RR, Tran R, Mathies RA (2009) Mapping GFP structure evolution during proton transfer with femtosecond Raman spectroscopy. Nature 462:200-204

Higashino A, Mizuno M, Mizutani Y (2016) Chromophore structure of photochromic fluorescent protein Dronpa: acid-base equilibrium of two cis configurations. J Phys Chem B 120:3353

Lelimousin M, Noirclerc-Savoye M, Lazareno-Saez C, Paetzold B, Le VS, Chazal R, Macheboeuf P, Field MJ, Bourgeois D, Royant A (2009) Intrinsic dynamics in ECFP and Cerulean control fluorescence quantum yield. Biochemistry 48:10038-10046

Loos Davey C, Habuchi Satoshi, Flors Cristina, Hotta Junichi, Jörg Wiedenmann G, Nienhaus Ulrich, Hofkens Johan (2006) Photoconversion in the red fluorescent protein from the sea anemone Entacmaea quadricolor: is cis - trans isomerization involved? J Am Chem Soc 128:6270-6271

Patterson G, Day RN, Piston D (2001) Fluorescent protein spectra. J Cell Sci 114:837-838

Tu AT (1982) Raman spectroscopy in biology: principles and applications. Wiley, New York

Tuma R (2005) Raman spectroscopy of proteins: from peptides to large assemblies. J Raman Spectrosc 36:307-319

Voityuk AA, Michel-Beyerle ME, Rösch N (1998) Quantum chemical modeling of structure and absorption spectra of the chromophore in green fluorescent proteins. Chem Phys 231(1):13-25

Wachter RM, Elsliger MA, Kallio K, Hanson GT, Remington SJ (1998) Structural basis of spectral shifts in the yellowemission variants of green fluorescent protein. Structure 6:1267-1277

Xu Y (2005) Raman spectroscopy in application of structure biology. In: Chapter 2 proteins. Chemical Industry Press, Beijing, pp 11-26 